\title{
Chimères embryonnaires et développement du système nerveux
}

Les cellules de caille peuvent être aisément reconnues de celles de poulet par la structure de leur noyau qui comporte une masse importante d'hétérochromatine associée au nucléole. Lorsqu'au cours de l'embryogenèse, on associe les cellules des deux espèces, soit en culture in vitro, soit en greffant in vivo des cellules de caille dans le poulet (ou vice versa), il est aisé de les identifier, quelle qu'ait été la durée de l'association. Nous disposons de plus, d'anticorps monoclonaux spécifiques de l'espèce caille ou poulet, ainsi que de certains types cellulaires. L'utilisation de ces marqueurs appliqués sur les tissus-chimères permet d'obtenir des renseignements précis sur les migrations cellulaires qui se produisent au cours de la morphogenèse, et sur l'origine embryologique de nombreux types cellulaires tels que ceux qui constituent la région faciale et le système nerveux périphérique. Ces greffes interspécifiques embryonnaires permettent aussi d'étudier l'histogenèse du cerveau ainsi que la détermination génétique de certains caractères comportementaux.

Nicole M. Le Douarin Marie-Aimée Teillet Gérard Couly

\section{ADRESSES}

N.M. Le Douarin : professeur au college de France. M.A. Teillet : chargée de recherche au Cnrs. G. Couly : professeur en stomatologie pédiatrique à l'hôpital des Enfants-Malades. Institut d'embryologie cellulaire et moléculaire du Cnrs et du Collège de France, 49 bis, avenue de la Belle-Gabrielle, 94736 Nogent- e terme de chimère désignait à l'origine un monstre de la mythologie grecque qui combinait la tête d'un lion, le corps d'une chèvre et la queue d'un serpent. Ce terme a été introduit en biologie par des botanistes au début du siècle (Winckler, 1907) dans des expériences où ils associaient les racines d'une plante à la tige d'une autre plante. Le tissu cicatriciel dont la croissance était induite à la jonction des deux composants était appelé chimère. Quelques années auparavant, Harrison (1903) avait produit des chimères animales entre deux espèces de grenouille sans toutef ois les désigner par ce mot. C'est Spemann (1924) qui, vingt ans plus tard, l'a rendu populaire dans sa célèbre expérience sur l'organisateur où il a implanté la lèvre dorsale du blastopore de la gastrula de Triturus taeniatus pigmenté, sur la face ventrale de Triturus cristatus dépourvu de pigment induisant ainsi un embryon surnuméraire. La présence du marqueur pigmentaire lui a permis d'analyser à l'échelle cellulaire les résultats de l'expérience et de découvrir le phénomène d'induction embryonnaire dont l'importance en embryologie a été considérable. Le développement d'un embryon puis d'un adulte dans toute sa complexité à partir d'une cellule unique, l'œuf fécondé, est, en effet, une des questions les plus difficiles de la biologie. Le développement embryonnaire comporte, à côté des divisions 
et de la différenciation des cellules issues de l'œuf, la mise en œuvre de mouvements cellulaires qui assurent la réalisation de la forme caractéristique des organes et du corps, génétiquement déterminée pour chaque espèce.

L'analyse de la morphogenèse embryonnaire est difficile surtout dans le cas d'organismes aussi complexes que les vertébrés. Pouvoir utiliser des marqueurs permettant de visualiser et de suivre le comportement des cellules au cours de l'embryogenèse constitue un atout majeur dans l'étude de ces processus fondamentaux du développement.
La combinaison de cellules d'espèces différentes, mais proches au plan taxonomique, peut être à cet égard intéressante, à condition que ces cellules se distinguent par des caractéristiques génétiques stables et aisément identifiables.

Ces conditions sont réalisées entre deux espèces d'oiseaux, la caille et le poulet. Elles nous ont amenés à construire des embryons chimériques par combinaison de tissus provenant de ces deux espèces et à étudier par ce moyen le développement du système nerveux.

Chez les vertébrés, le système nerveux provient dans sa totalité du feuillet ectodermique. Sous l'influence d'une induction émanant du chordomésoderme, un épaississement de l'ectoderme apparaît sur la face dorsale de la gastrula et constitue la plaque neurale, c'est-à-dire l'ébauche neurale primitive. Celle-ci est à l'origine du système nerveux central et de la quasi-totalité du système nerveux périphérique à la genèse duquel participent aussi les placodes ectodermiques céphaliques.

La mise en place des structures hautement organisées qui constituent le système nerveux fait intervenir des mouvements morphogénétiques particulièrement complexes lors de la

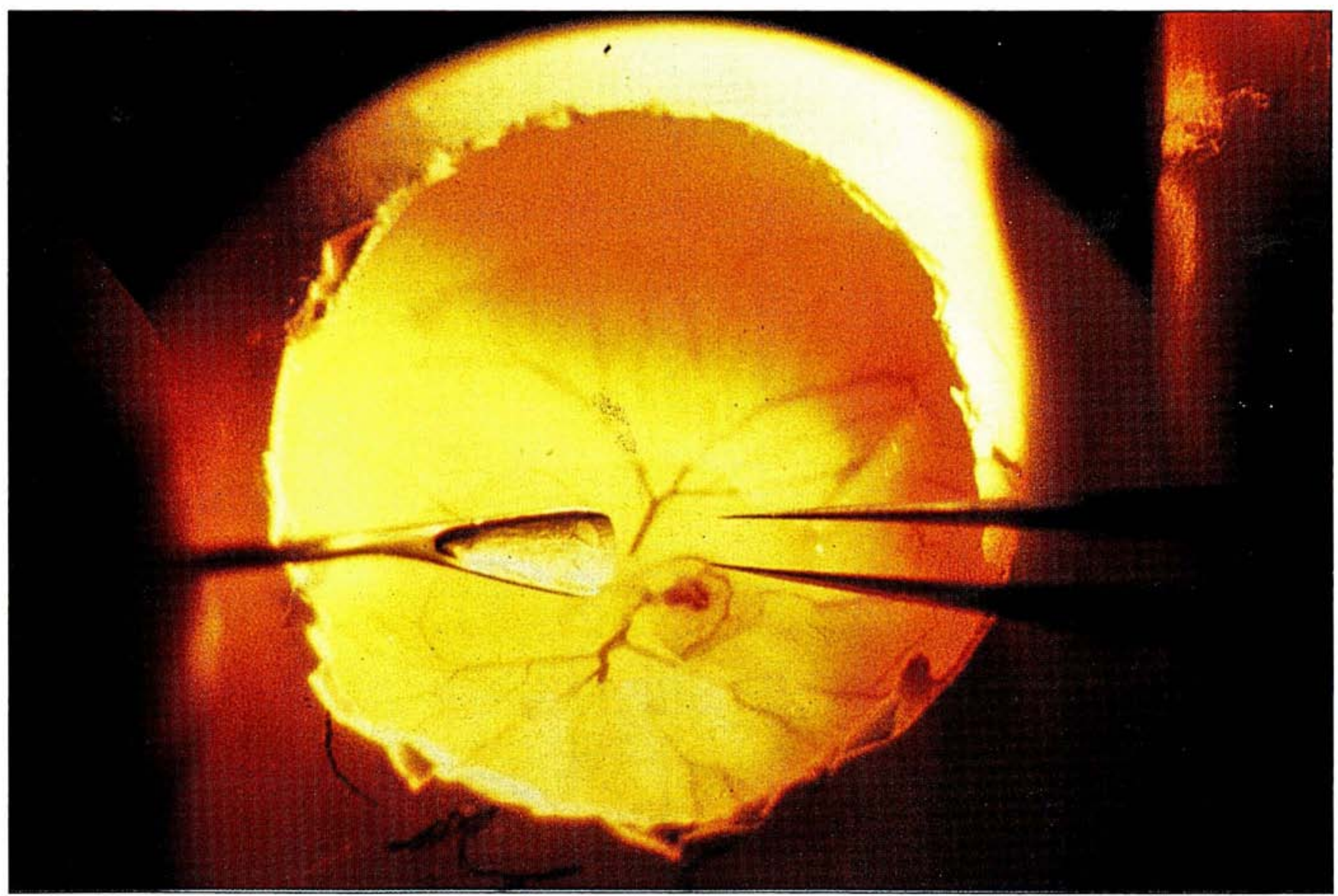

Figure 1. Embryon de poulet de deux jours et demi d'incubation dans l'œuf. Dès les plus jeunes stades, il est possible d'intervenir in ovo après avoir ouvert une fenêtre dans la coquille. L'œuf, refermé et incubé dans des conditions de température et d'humidité contrôlées, continue son développement. (Photo P. Plailly, Cnrs.)

$\mathrm{m} / \mathrm{s} n^{\circ} 3$ vol. 6, mars 90 
formation du tube neural et de l'édification de l'encéphale. Chez les vertébrés supérieurs notamment, oiseaux et mammiferes, le tube neural subit au cours de la céphalogenèse des courbures et des déformations spectaculaires qui, finalement, sculptent la forme définitive qu'a le cerveau dans chaque espèce. Les mécanismes responsables de la morphogenèse neurale sont difficiles à analyser. Les courbures du tube neural sont certes en partie dépendantes de la morphogenèse générale de la tête, c'est-à-dire du comportement des autres territoires céphaliques, mais ils font aussi intervenir des caractéristiques propres au tube neural lui-même.

Deux phénomènes jouent à cet égard un rôle essentiel, la croissance diffé-

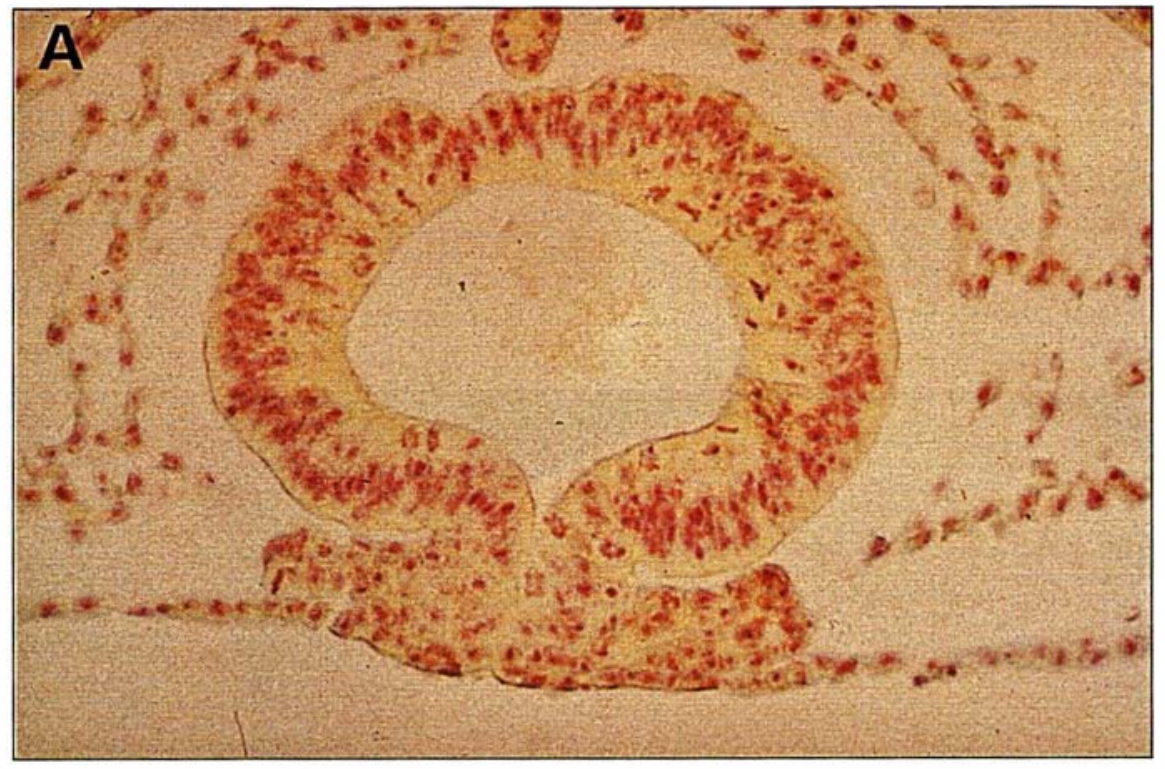

rentielle des territoires de l'épithélium ventriculaire et les migrations individuelles des cellules qui le constituent. Certaines zones de l'épithélium neural sont, à des stades strictement définis du développement, le site d'une activité mitotique particulièrement intense, alors que dans d'autres régions, les cellules de l'épithélium ventriculaire se multiplient moins vite. La régulation de l'activité mitotique locale au sein du tube neural primitif est une question à laquelle virtuellement aucune réponse n'a jusqu'ici été apportée. Les migrations cellulaires, en revanche, ont fait l'objet d'études actives.

Au cours de la première moitié de ce siècle, le matériel de prédilection des embryologistes était l'embryon de grenouille ou de triton et les travaux des pionniers ont porté sur ces espèces.

Plus récemment, l'embryon d'oiseau - très proche de celui des mammiferes et accessible à l'expérimentation dans l'œuf, pendant toute la période du développement (figure 1, p. 229) - s'est substitué, pour nombre d'études portant sur le système nerveux, à celui des amphibiens. Depuis la mise au point d'une méthode de marquage cellulaire fondée sur la construction de chimères entre embryons de caille et de poulet [1], il présente des avantages certains pour l'étude de nombreux problèmes de morphogenèse.

Figure 2. (A) Coupe transversale au niveau du mésencéphale d'un embryon de caille d'un jour et demi d'incubation (7 somites). Les cellules de crête neurale s'individualisant de l'ébauche neurale sont visibles dorsalement par rapport au tube nerveux (coloration de Feulgen).

(B) Préparation observée en microscopie à balayage montrant l'ébauche neurale troncale d'un embryon de poulet au moment où les cellules de crête neurale commencent

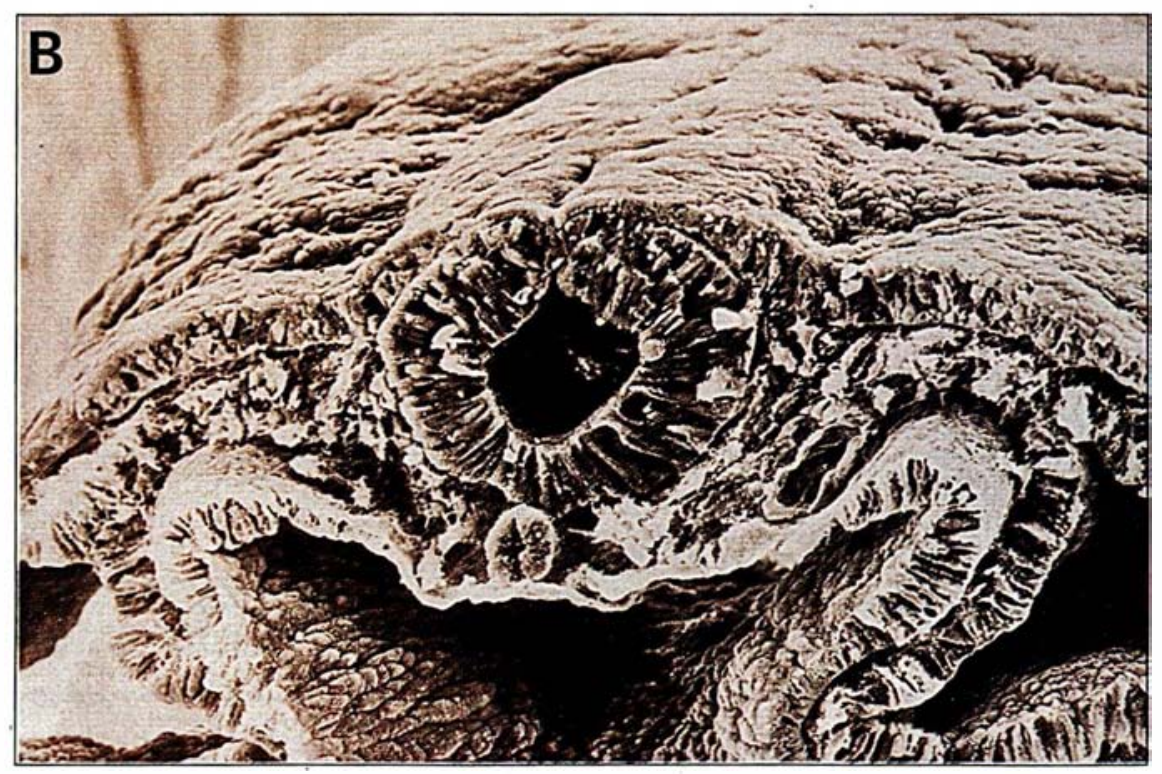




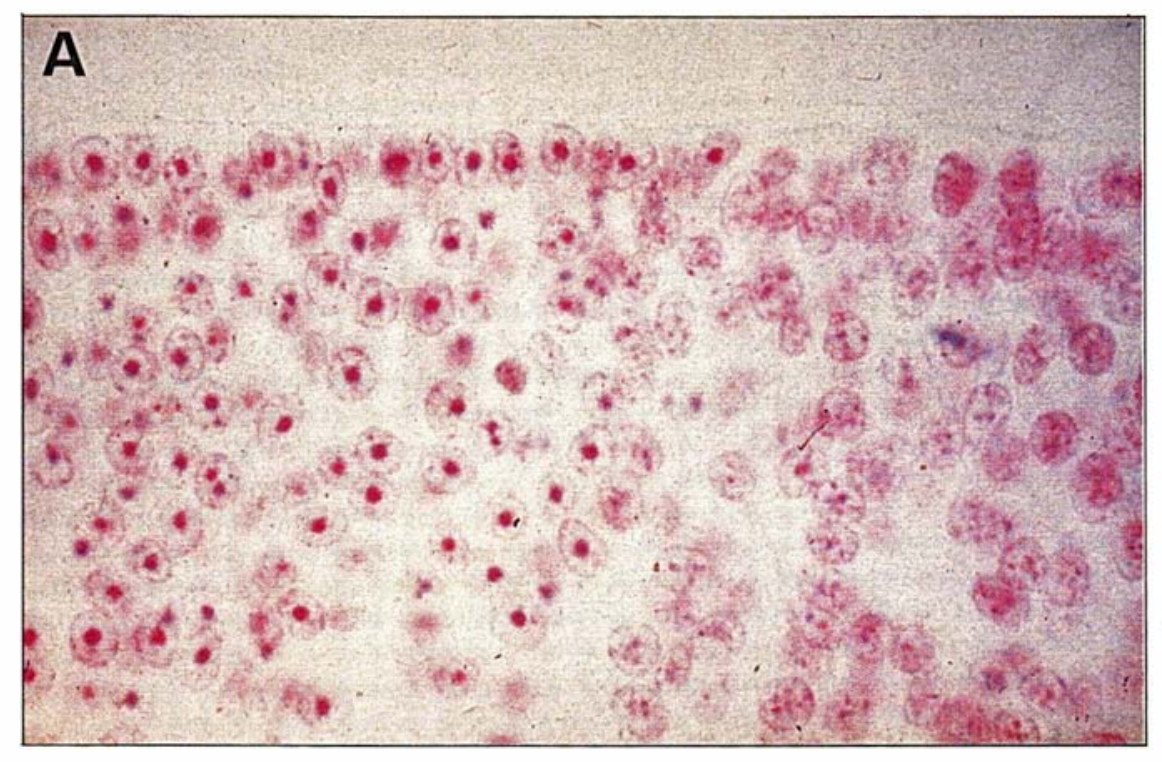

Figure 3. (A) Épithélium rneural chimère (caille-poulet) coloré selon la technique de Feulgen. Les cellules de caille montrent une volumineuse masse d'hétérochromatine centronucléaire. Dans les cellules de poulet, I'hétérochromatine est dispersée dans le noyau. (B) Sur des coupes colorées par l'orange d'acridine et observées avec une lumière ultraviolette, la masse d'hétérochromatine des cellules de caille apparaît fortement fluorescente.

Nous avons particulièrement étudié l'ontogenèse de la crête neurale, une structure dérivée de l'ébauche neurale primitive, qui est à l'origine de la plupart des éléments qui composent le système nerveux périphérique et aussi de nombreux autres types cellulaires.

La crête neurale se forme selon un gradient cranio-caudal lors de la fermeture du tube neural et résulte de la fusion des bords latéraux de la plaque neurale (figure 2). Outre ses potentialités multiples, la crête neurale constitue un modèle d'étude du développement particulièrement intéressant car il permet d'aborder des problèmes de morphogenèse. En effet, avant de se différencier, les cellules des crêtes neurales effectuent dans l'embryon des migrations étendues.

Cet article présentera certaines des données principales résultant de cette étude ainsi que les perspectives récentes offertes par la construction de chimères chez l'embryon d'oiseau dans des recherches sur le développement du système nerveux central.

\section{Le système de marquage cellulaire caille-poulet}

Le marquage nucléaire. Cette méthode de marquage cellulaire est fondée sur une observation faite par $\mathrm{m} / \mathrm{s} \mathrm{n}^{\circ} 3 \mathrm{vol} .6$, mars 90

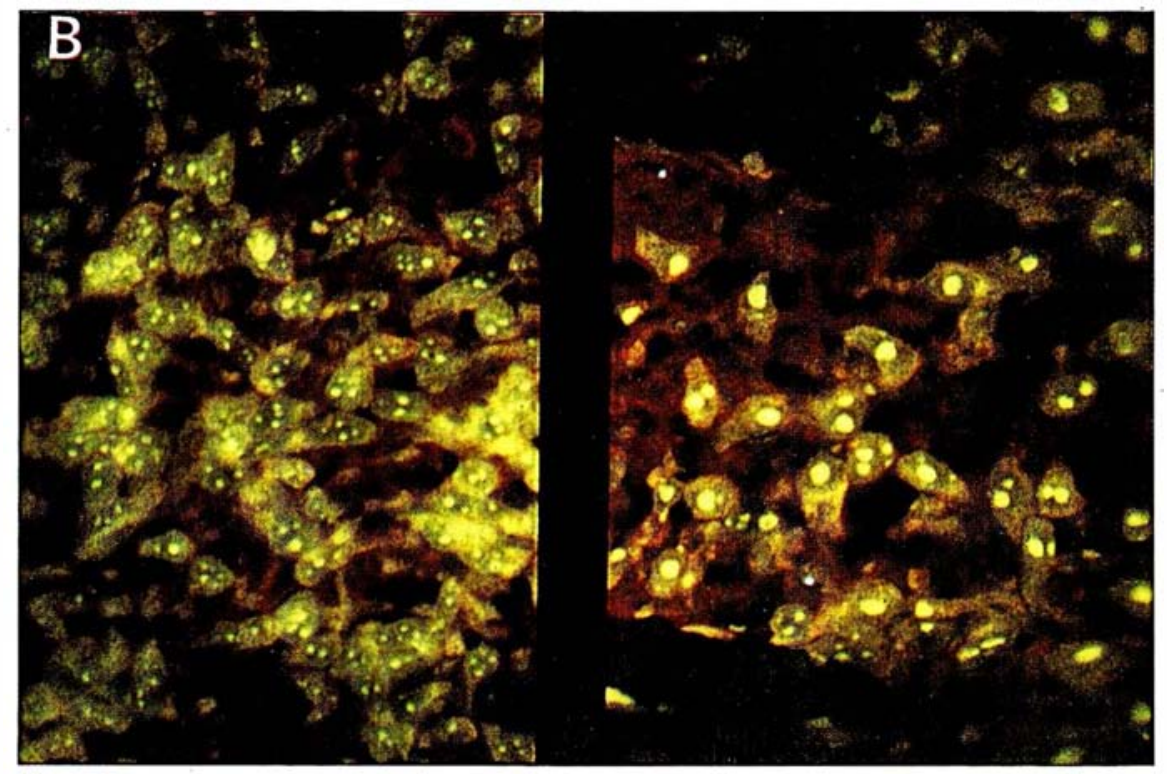

N. Le Douarin en 1969 [1] sur la structure particulière du noyau interphasique chez la caille japonaise (Coturnix coturnix japonica). Dans toutes les cellules embryonnaires et adultes de cette espèce, l'hétérochromatine constitutive est condensée en une masse, généralement centronucléaire, associée aux nucléoles. Une telle disposition de la chromatine se rencon- tre rarement dans le règne animal (encore qu'elle soit observée chez des oiseaux autres que la caille [2]) et differe nettement de celle qui prévaut chez les mammifères (homme, souris, rat...) et chez le poulet, où l'hétérochromatine est dispersée dans le nucléoplasme sous la forme de chromocentres de petite taille.

Il en résulte que, si des cellules 


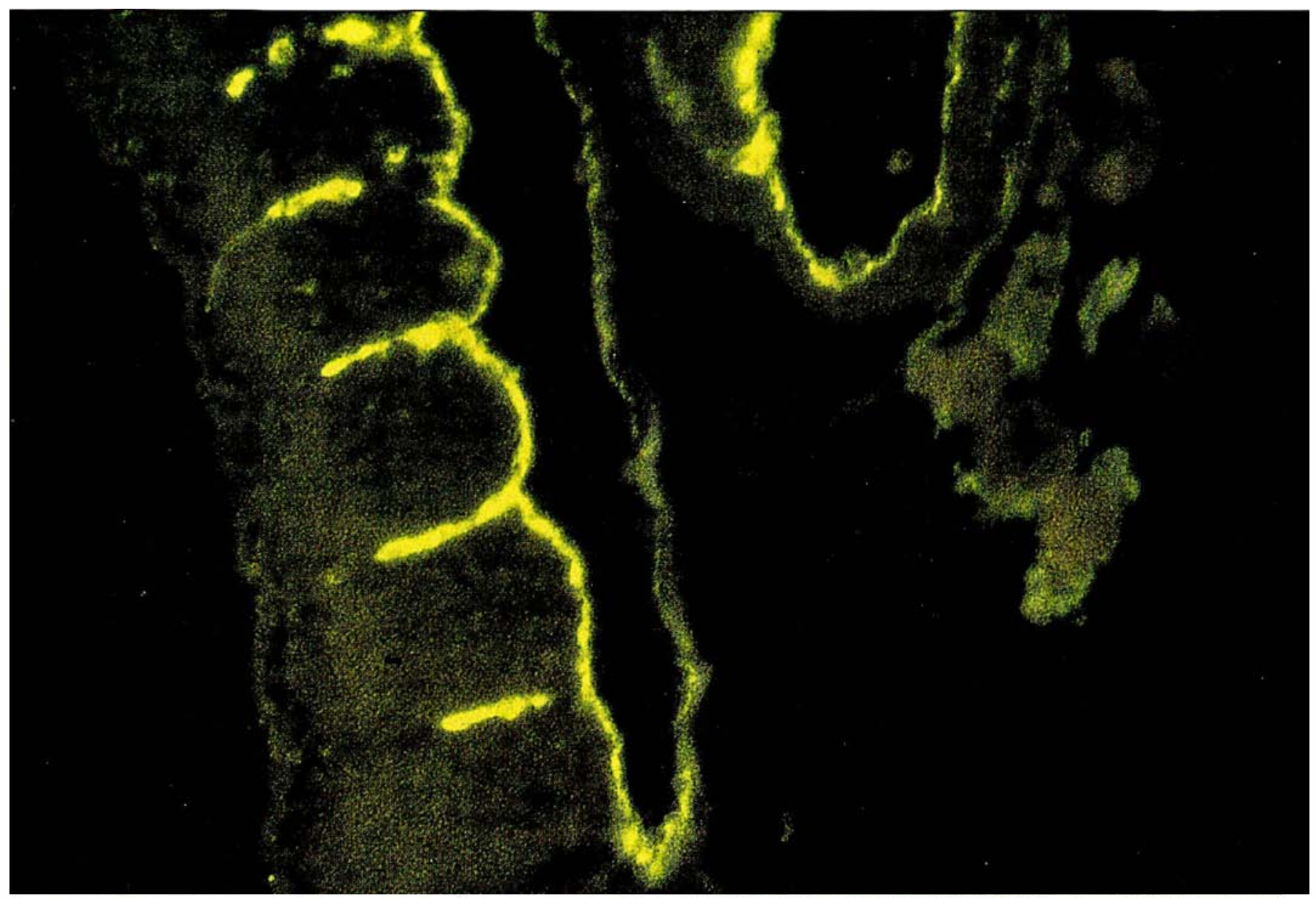

Figure 4. L'anticorps MB1, révélé par la fluorescéine, a été appliqué sur un jeune blastoderme de caille. Les cellules endothéliales de l'aorte et des vaisseaux segmentaires sont immunoréactifs et présentent une fluorescence verte. .

embryonnaires de caille et de poulet sont expérimentalement associées, elles conservent leur identité morphologique et peuvent être reconnues les unes des autres grâce au volumineux nucléole riche en $\mathrm{ADN}$ des cellules de caille (figure 3, p. 231). La stabilité du marqueur nucléaire de la caille est remarquable, puisque la masse d'hétérochromatine centronucléaire subsiste dans tous les types cellulaires différenciés, même si la structure interne du nucléole présente quelques variations selon le tissu considéré [3]. Cette méthode de marquage cellulaire est donc d'un usage facile et d'une grande précision. En effet, une cellule unique de caille peut aisément être reconnue au sein d'un tissu de poulet. Elle s'est révé- lée supérieure aux techniques utilisées auparavant, fondées sur le marquage du noyau par la thymidine tritiée ou du cytoplasme par des colorants vitaux, eu égard à sa facilité d'emploi ainsi qu'à la précision et à la stabilité du marquage qu'elle confere aux cellules dont on cherche à suivre la destinée au cours de l'ontogenèse. La caille et le poulet (Gallus gallus) sont deux espèces proches au plan taxonomique. Elles appartiennent à la famille des Phasianidés mais diffèrent par plusieurs paramètres tels que la taille à la naissance (le poulet pèse environ 50 grammes et la caille 10 grammes) et la durée de l'incubation (21 jours chez le poulet et 17 jours chez la caille). Cependant la taille des embryons est à peu près identique pendant la première semaine de l'incubation et la chronologie du développement embryonnaire ne diffère que très peu dans les deux espèces. Il en résulte que les chimères qu'on construit dans l'œuf en remplaçant un territoire embryonnaire par l'équivalent provenant de l'autre espèce sont viables, même lorsque le chimérisme porte sur le système nerveux central et l'encéphale.

Le marquage des tissus chimères par des anticorps spécifiques d'espèce. Le marqueur nucléaire est mis en évidence par des colorants de l'ADN tels que la réaction de Feulgen ou des composés fluorescents ayant une affinité pour l'ADN (bisbenzimide-Hoechst 33258, oran- 
ge d'acridine) (figure $3 B$ ). Il peut aussi être observé au microscope électronique [3]. Dans tous les cas, on peut associer les méthodes de détection de l'hétérochromatine nucléolaire à d'autres techniques permettant d'identifier le type cellulaire considéré par des constituants cytoplasmiques ou membranaires caractéristiques. Depuis quelques années, la panoplie des réactifs utilisés pour étudier les tissus chimères s'est enrichie d'anticorps généralement monoclonaux à la fois spécifiques de l'espèce caille ou poulet et d'un type cellulaire donné. Ainsi, les anticorps $\mathrm{MB} 1$ et $\mathrm{QH} 1$ permettent d'identifier les cellules endothéliales et les leucocytes de caille à l'exclusion de ceux du poulet $[4,5]$ (figure 4) et sont de précieux outils pour l'étude du développement des lignées hémangioblastiques.

Les différentes sous-populations de lymphocytes thymodépendants de poulet peuvent être identifiées par des anticorps spécifiques des chaînes $\gamma \delta$ et $\alpha \beta$ du récepteur spécifique des cellules $\mathrm{T}$ (respectivement TCR 1 et TCR2) et des molécules qui lui sont associées, équivalentes des antigènes CD3, CD4, CD8 de la souris (anticorps $\left.\mathrm{CT}_{3}, \mathrm{CT}_{4}, \mathrm{CT}_{8}\right)$. Ces réactifs ne reconnaissent pas les molécules correspondantes de caille, $[6,7]$ et peuvent être utilisés sur des tissus chimères, permettant ainsi d'effectuer dans des conditions privilégiées certaines analyses de l'ontogenèse de la fonction $\mathrm{T}$ chez les oiseaux [8].

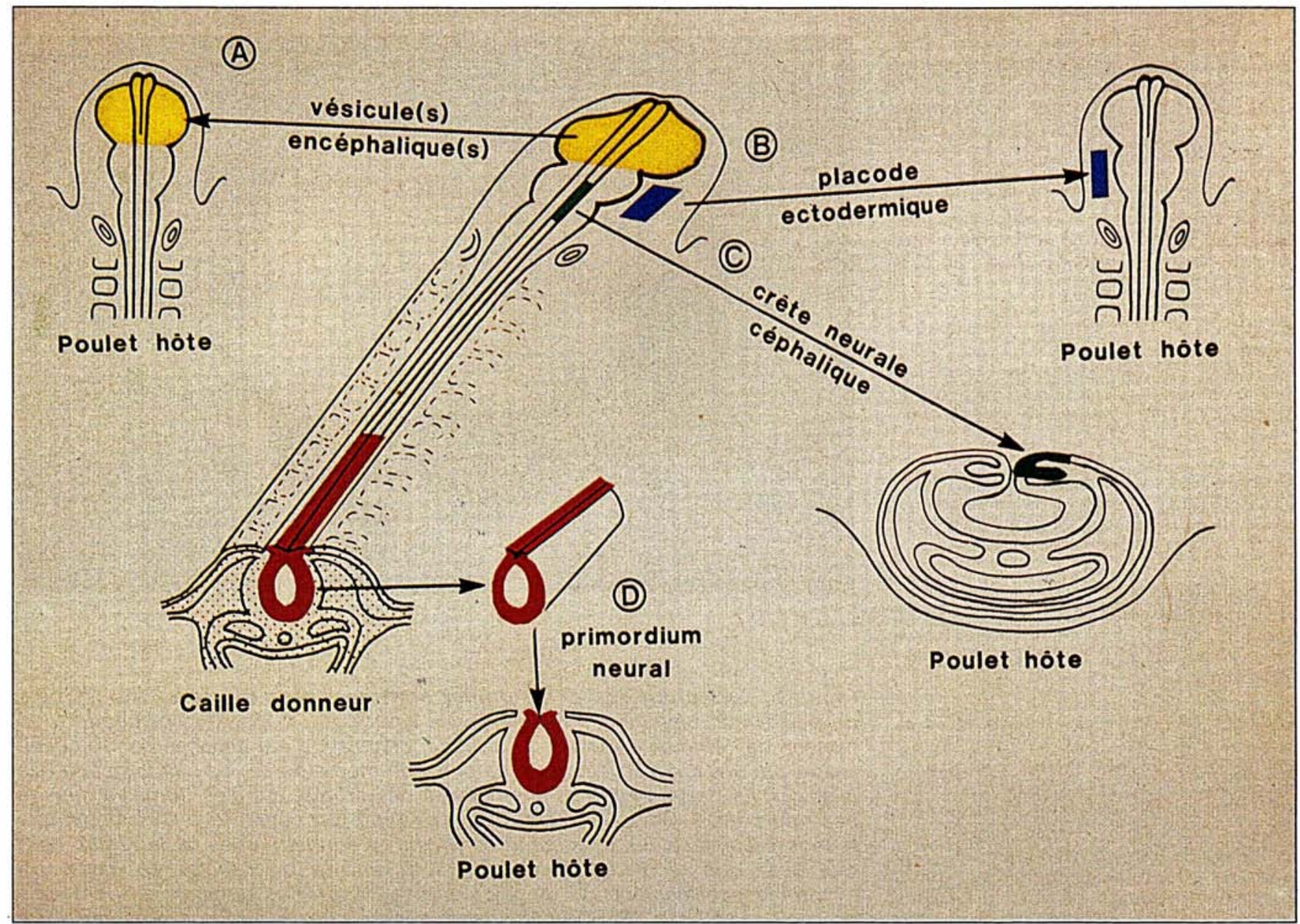

Figure 5. La greffe de tissus de caille chez le poulet et inversement peut être utilisée pour marquer tout territoire embryonnaire. Différents types de greffe sont pratiqués pour étudier le développement du système nerveux central et du système nerveux périphérique.

$\boldsymbol{A}=$ remplacement $d^{\prime} u n e$ ou plusieurs vésicules encéphaliques; $\boldsymbol{B}=$ remplacement $d^{\prime} u n$ territoire placodal $; \boldsymbol{C}=$ remplacement d'un fragment de bourrelet neural; $\boldsymbol{D}=$ remplacement $d^{\prime} u n$ troncon de l'ébauche neurale. Pour $\boldsymbol{A}$ $\boldsymbol{B}$ et $\boldsymbol{C}$, le prélèvement s'effectue microchirurgicalement chez le donneur comme chez le receveur. Pour $\boldsymbol{D}$, le prélèvement est facilité par une dissociation enzymatique permettant de greffer le tronçon d'ébauche neurale à l'exclusion de tout autre tissu.

$m / s n^{\circ} 3$ vol. 6 , mars 90 


\section{RÉFÉRENCES}

1. Le Douarin NM. Particularités du noyau interphasique chez la caille japonaise (Coturnix coturnix japonica). Utilisation de ces particularités comme "marquage biologique ". Bull Biol Fr Belg 1969; 103: 435-52.

2. Le Douarin NM. La structure du noyau interphasique chez différentes espèces d'oiseaux. CR Acad Sci (Paris) 1971 ; 272 : $1402-4$.

3. Le Douarin NM. Étude ultrastructurale comparative du noyau interphasique chez la caille (Coturnix coturnix japonica) et le poulet (Gallus gallus) par la méthode de coloration régressive à l'EDTA. CR Acad Sci (Paris) $1971 ; 272$ : 2334-7.

4. Péault BM, Thiery JP, Le Douarin NM. Surface marker for hemopoietic and endothelial cell lineages in quail that is defined by a monoclonal antibody. Proc Natl Acad Sci USA 1983 ; 80 : 2976-80.

5. Pardanaud L, Altman C, Kitos P, Dieterlen-Lièvre F, Buck CA. Vasculogenesis in the early quail blastodisc as studied with a monoclonal antibody recognizing endothelial cells. Development 1987 ; 100 : $339-49$.

6. Chan MM, Chen CL, Ager LL, Cooper MD. Identification of the avian homologues of mammalian CD4 and CD8 antigens. $J$ Immunol $1988 ; 140: 2133-8$.

7. Chen $\mathrm{CH}$, Cihak J, Lösch U, Cooper M. Differential expression of two $\mathrm{T}$ cell receptors TCR1 and TCR2, on chicken lymphocytes. Eur J Immunol $1988 ; 18$ 539-43.

8. Coltey M, Bucy RP, Chen $\mathrm{CH}$, et al. Analysis of the first two waves of thymus homing stem cells and their T cell progeny in chick-quail chimeras. J Exp Med 1989; 170 : 543-57.

9. Takagi S, Tsuji T, Kinutani M, Fujisawa $H$. Monoclonal antibodies against species-specific antigens in the chick central nervous system: putative application as transplantation markers in the chick-quail chimera. J Histochem Cytochem 1989 ; 37 : 177-84.

10. Lance-Jones CC, Lagenaur CF. A new marker for identifying quail cells in embryonic avian chimeras: quail-specific antiserum. J Histochem Cytochem 1987; 35
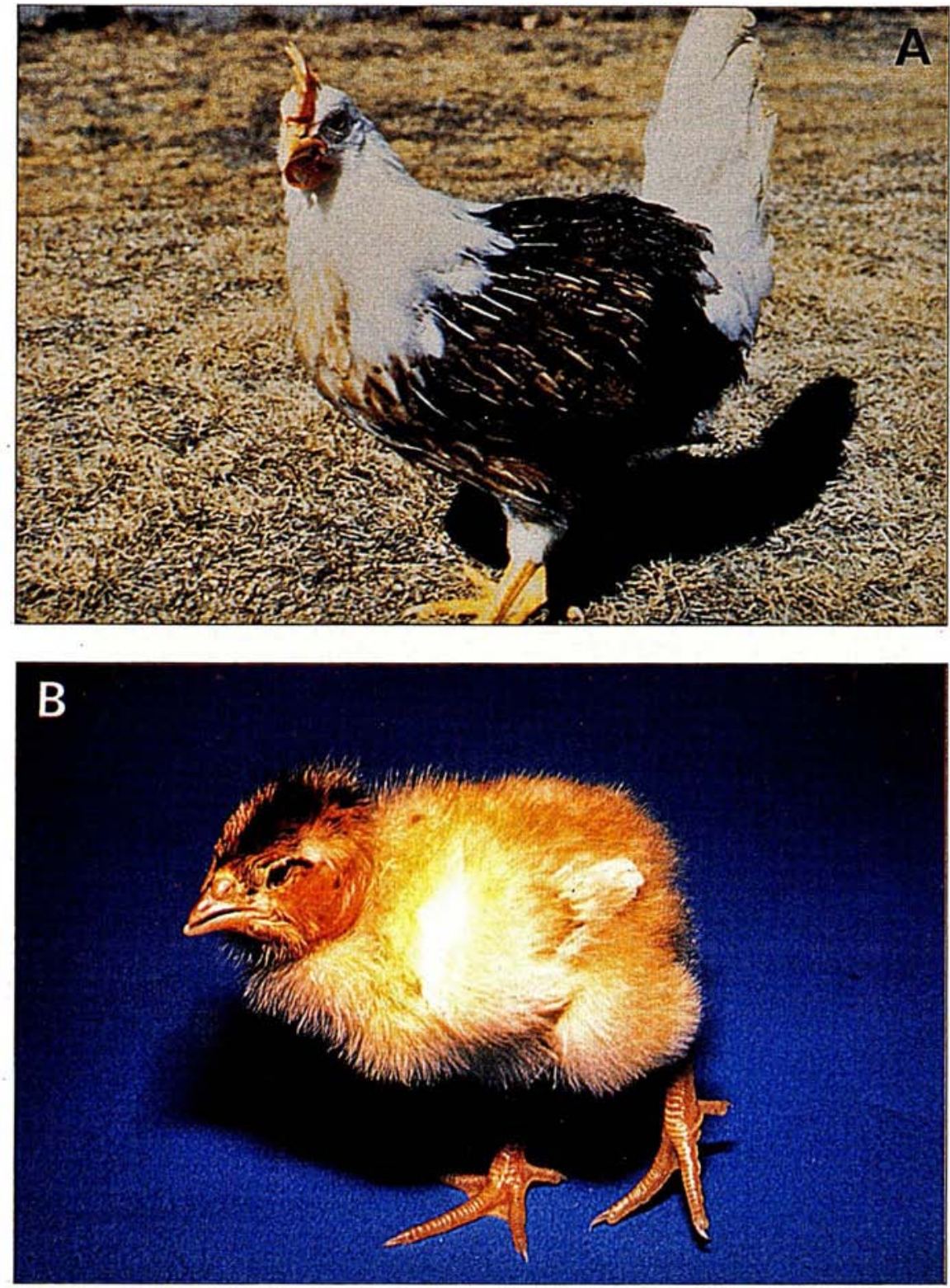

Figure 6. Les chimères caille-poulet sont capables d'éclore. (A) Chimère de deux mois environ chez laquelle, au cours du $2^{\theta}$ jour de l'incubation, un tronçon de l'ébauche neurale de la région brachiale a été échangé contre l'équivalent prélevé chez un embryon de caille de même stade. La pigmentation des ailes résulte de la migration des cellules des crêtes neurales de caille dans la peau du poulet. Chez une chimère de ce type, on constate à l'histologie que la moelle épinière, les ganglions rachidiens et sympathiques de la région opérée, ainsi que la médullo-surrénale, sont formés de cellules de caille. Un syndrome neurologique dû au rejet des tissus greffés apparaît aux environs de deux mois [31]. (B) Chimère de huit jours chez laquelle le prosencéphale et le mésencéphale ont été remplacés par les mêmes vésicules encéphaliques prises chez l'embryon de caille. Le bec supérieur formé de cellules provenant des crêtes neurales mésencéphaliques de caille est plus court que le bec inférieur qui a pour origine des cellules de l'hôte. La pigmentation des plumes céphaliques est celle du donneur. Cette chimère - dont les hémisphères cérébraux et le cerveau moyen étaient composés de cellules de caille - a présenté, après action de la testostérone, un chant structuré comme celui de la caille [30]. 
Des laboratoires japonais et américain ont produit des anticorps reconnaissant respectivement les neurones de poulet et la plupart des cellules de caille $[9,10]$. Les anticorps sont d'une grande utilité dans les recherches que nous-mêmes et d'autres chercheurs réalisons sur le développement du système nerveux.

\section{La construction des chimères neurales entre caille et poulet}

Le principe de la méthode mise au point en 1969 [1] et modifiée depuis, en fonction des besoins expérimentaux, est de remplacer un fragment de l'ébauche neurale d'une espèce par son équivalent exact provenant d'un embryon au même stade de l'autre espèce (figure 5 , p. 235). La caille et le poulet peuvent indifféremment être utilisés comme hôte ou donneur. Cependant, la facilité plus grande qu'il y a à reconnaître une cellule de caille dans un tissu de poulet que l'inverse nous a amenés à réaliser le plus souvent des greffes de la caille dans le poulet. Les embryons donneur et receveur étant au même stade, l'opération ne perturbe pratiquement pas le développement embryonnaire. Ainsi l'analyse des chimères permet-elle d'obtenir des renseignements sur les processus normaux de l'embryogenèse.

Les animaux résultant des expériences représentées sur la figure 5 se développent normalement. Même ceux dans lesquels des régions importantes de l'encéphale appartiennent à l'autre espèce sont capables d'éclore, de marcher, de répondre à des stimuli visuels et auditifs et d'interagir avec leur environnement comme d'autres oiseaux non opérés (figure 6). Cela ouvre des possibilités actuellement mises à profit pour étudier l'ontogenèse et le caractère génétique ou acquis de certains comportements.

Une étude systématique du devenir des cellules de crête neurale a été réalisée au moyen de greffes isochroniques et isotopiques de régions définies de l'ébauche neurale, réalisées à tous les niveaux du névraxe entre embryons de caille et de poulet ([11] pour revue). Elle a permis d'identifier des dérivés de la crête neurale jusque-là non connus, d'établir le $\mathrm{m} / \mathrm{s} n^{\circ} 3$ vol. 6 , mars 90 niveau d'origine et les voies de migration des cellules formant les systèmes ganglionnaires sensoriel et autonome ainsi que les paraganglions catécholaminergiques et de montrer le rôle majeur joué par la crête neurale céphalique dans la genèse des structures conjonctives et squelettiques de la face et du cou [12-15]. La liste des dérivés identifiés de la crête neurale, indiquée dans le Tableau I, révèle l'extraordinaire diversité des types cellulaires dérivant de cette structure.

\section{Crête neurale et morphogenèse céphalique}

Les recherches effectuées sur le devenir des crêtes neurales céphaliques constituent un exemple représentatif des potentialités offertes par la tech- nique des chimères caille-poulet dans l'analyse du développement embryonnaire. Chez les vertébrés supérieurs, l'ontogenèse céphalique est en effet le résultat de processus morphogénétiques très complexes que l'embryologie descriptive n'avait pas été capable de décrypter.

C'est grâce à des travaux de pionniers tels que His (1868), Goronovitch (1893), Platt (1895) qu'à la fin du siècle dernier, l'intervention de cellules issues de la crête neurale céphalique dans la formation du squelette hypobranchial a été proposée sur la base d'observations histologiques fines réalisées sur l'embryon d'amphibien et d'oiseau. La preuve expérimentale de ce phénomène de migration cellulaire massive n'a été apportée que plus tard lorsque Raven (1931), Hörstadius et Sellman (1941) puis, à partir de 1966, Chibon ont

\begin{tabular}{|c|c|}
\hline & $\begin{array}{c}\text { Tableau I } \\
\text { DF́RIVÉS DF LA CRF̂TF NFURAIF }\end{array}$ \\
\hline Neurones & $\begin{array}{l}\text { Ganglions sensoriels de certains nerfs crâniaux } \\
\text { Ganglions spinaux } \\
\text { Ganglions des systèmes nerveux autonomes sympathi- } \\
\text { que et parasympathique }\end{array}$ \\
\hline $\begin{array}{c}\text { Cellules non } \\
\text { neuronales } \\
\text { du système } \\
\text { nerveux } \\
\text { périphérique }\end{array}$ & $\begin{array}{l}\text { Cellules satellites } \\
\text { Cellules de Schwann }\end{array}$ \\
\hline $\begin{array}{l}\text { Cellules } \\
\text { endocrines } \\
\text { ou para- } \\
\text { endocrines }\end{array}$ & $\begin{array}{l}\text { Cellules médullaires de la surrénale } \\
\text { Paraganglions adrénergiques } \\
\text { Cellules à calcitonine } \\
\text { Cellules de type I du corps carotidien }\end{array}$ \\
\hline \multicolumn{2}{|l|}{$\begin{array}{l}\text { Cellules } \\
\text { pigmentaires }\end{array}$} \\
\hline Méninges & Des hémisphères cérébraux \\
\hline Mésectoderme & $\begin{array}{l}\text { Squelette viscéral et facial et partie du squelette crânial } \\
\text { Odontoblastes } \\
\text { Tissu conjonctif et musculaire de la paroi des gros vais- } \\
\text { seaux dérivés des arcs aortiques } \\
\text { Tissu conjonctif des glandes pituitaires, lacrymales, sali- } \\
\text { vaires, thyroïde, parathyroïdes et du thymus } \\
\text { Contribution aux muscles striés de la face et du cou }\end{array}$ \\
\hline
\end{tabular}


utilisé des marqueurs cellulaires pour étudier ce problème. Ces marqueurs fondés sur l'utilisation de colorants vitaux (Raven), de différences plus ou moins nettes entre les cellules de différentes espèces d'amphibiens (Hörstadius) ou sur le marquage des noyaux en division par la thymidine tritiée (Chibon) ne présentaient cependant pas la stabilité nécessaire pour qu'une étude à long terme des migrations pût être réalisée. Chez les vertébrés supérieurs, les seules informations concernant le rôle de la crête neurale dans la genèse de la tête provenaient des expériences de $\mathrm{Ham}$ mond et Yntema $(1953,1964)$ consistant à exciser les crêtes neurales du cerveau postérieur et à observer les déficiences consécutives à l'opération. Cette méthode révélait certainement la participation de cellules issues de l'ébauche neurale à la formation des pièces squelettiques de l'arc mandibulaire et hyoïdien. Cependant, les capacités régulatrices considérables de l'embryon précoce des vertébrés empêchaient une évaluation précise de la contribution de la crête neurale à ces structures.

En revanche, dans la construction des chimères, le remplacement du territoire embryonnaire enlevé, par son équivalent issu d'un autre embryon, prévient les phénomènes de régulation observés après la simple ablation. On pouvait alors montrer que la crête neurale a un rôle plus important dans la formation de la tête qu'on ne le supposait jusqu'alors (figure 7). On démontrait en effet que la totalité du squelette facial et hypobranchial en dérive [13, 15-18]. Il apparaissait, en outre, que le derme de la face et de la partie ventrale du cou ainsi que la paroi musculoconjonctive des gros troncs aortiques issus du cœur proviennent aussi de la crête neurale ([11] pour revue). L'endothélium vasculaire, cependant, était toujours originaire de l'hôte dans tous les tissus dérivés de la crête neurale. Cette étude, ainsi que d'autres plus récentes fondées sur l'utilisation de l'anticorps a-MB1, révélait que la lignée hémangioblastique est d'origine strictement mésodermique et ne dérive jamais du mésectoderme.

Nous avons aussi pu montrer que la crête neurale céphalique est à l'ori- gine des cellules productrices de calcitonine qui se développent dans le corps ultimobranchial (dérivé de la $4^{\mathrm{e}}$ poche branchiale) chez tous les vertébrés et qui, chez les mammifères, migrent ensuite dans la glande thyroïde où elles constituent les cellules parafolliculaires [19-21]. Nous avons également démontré l'origine embryologique complexe des méninges : celles qui recouvrent les hémisphères cérébraux sont dérivées de la crête neurale céphalique, alors que celles de la moelle épinière et des autres parties de l'encéphale sont d'origine mésodermique.

Le bourrelet neural céphalique, cependant, n'est pas entièrement dévolu à la genèse de la crête neurale. Celle-ci ne prend naissance qu'à partir du niveau du diencéphale. En avant, l'ectoderme neural a une destinée jusque-là insoupçonnée que nous avons pu mettre en évidence en pratiquant des greffes de caille sur le poulet à des stades plus précoces du développement, ceux de la neurula (0 à 3 paires de somites [22-24]).

Pour cela, le bourrelet neural rostral est divisé en une région antérieure et médiane de $150 \mu \mathrm{m}$ de large et une région antérolatérale de $450 \mu \mathrm{m}$, ellemême segmentée en trois fragments successifs A, B, C de $150 \mu \mathrm{m}$. Chacun de ces territoires est prélevé chez le poulet et remplacé par le même territoire provenant d'une caille de même stade.

Ces expériences ont révélé que les territoires présomptifs de l'adénohypophyse et de l'hypothalamus sont étroitement associés et situés dans la partie la plus rostrale de la plaque neurale (figure $8, A$ et $B$, p. 238-239). L'unité neuroendocrinienne hypothalamo-adénohypophysaire est donc initialement contenue dans un territoire neural unique qui se sépare pendant la morphogenèse neurale en deux entités distinctes réunies par des liens fonctionnels étroits (figure 9, p. 240). Nous avons aussi pu déterminer la localisation de l'appareil olfactif par une série de greffes microchirurgicales intéressant le bourrelet neural latéral prosencéphalique. Celui-ci est à l'origine non seulement de la placode olfactive qui se différencie plus tard en épithélium et nerf olfactifs (zone A), mais il fournit aussi la totalité de la muqueuse de la fosse nasale 


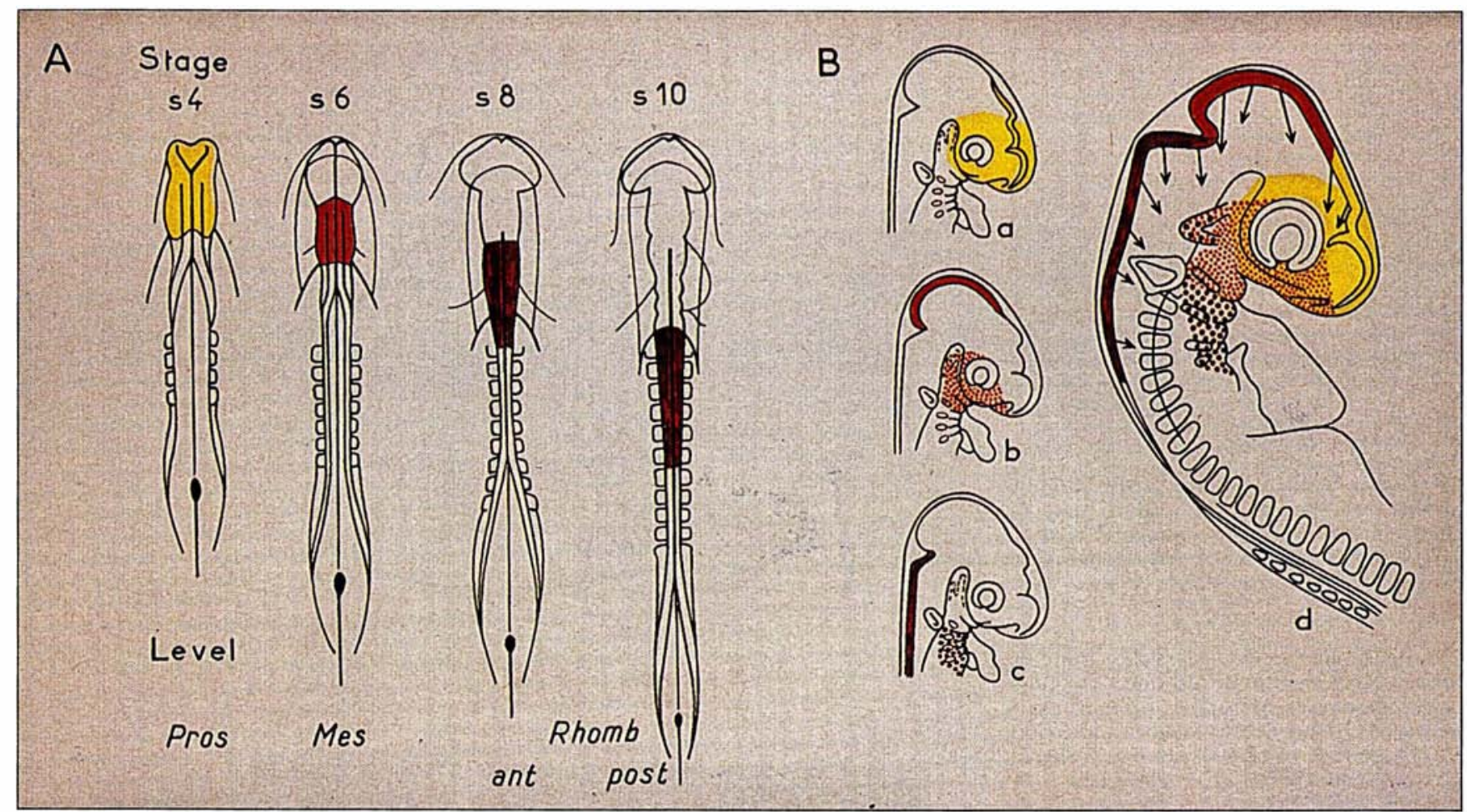

Figure 7. (A) Différents types de greffes réalisées chez des embryons de 4 à 10 somites pour l'étude des déri 'és mésectodermiques des crêtes neurales céphaliques. (B) Localisation des cellules des crêtes neurales issues de ces greffons après migration au niveau de la face et des régions branchiales. Les cellules des crêtes neurales prosencéphaliques sont marquées en jaune (a); celles des crêtes mésencéphaliques en petits points rouges (b) et celles des crêtes neurales rhombencéphaliques en gros points rouges $(c)$; (d) : récapitulation des données chez l'embryon de quatre jours d'incubation. Ces cellules constitueront chez l'adulte le squelette viscéral et facial et une partie du squelette crânial, du tissu conjonctif et musculaire de la face et du cou et de la paroi de gros vaisseaux ainsi que le tissu conjonctif de certaines glandes.

qui recouvre les cornets et le septum (zone B). Lorsque la greffe comporte en plus du bourrelet neural le segment adjacent de la plaque neurale, le rhinencéphale est formé de tissus neuroblastiques de caille. Ainsi l'appareil olfactif (épithélium sensoriel, nerf, aire de projection neurologique centrale) forme au stade neurula une unité neuro-sensorielle tout comme précédemment les territoires contigus de l'anté-hypophyse et de l'hypothalamus formaient une unité neuroendocrinienne (figure 9, p. 240). Le résultat le plus surprenant de ces expériences a été la démonstration que la peau recouvrant la partie médiane du frónt et du nez provient aussi du bourrelet neural prosencéphalique (zone C). Ainsi, les bords latéraux de la plaque neurale céphalique ont-ils $\mathrm{m} / \mathrm{s} n^{\circ} 3$ vol. 6 , mars 90 une destinée étonnamment variée allant de tissus endocriniens (adénohypophyse) et sensoriels (épithélium olfactif) au simple tissu épidermique (figure 9, p. 240). C'est en arrière de cette dernière région que la crête neurale proprement dite apparaît. Postérieurement, par rapport au territoire présomptif de l'épiphyse, les cellules du bourrelet neural ont un comportement particulier puisqu'elles perdent leurs propriétés épithéliales pour devenir migratrices.

\section{Le développement du système nerveux périphérique}

La méthode de marquage cellulaire résultant de la construction de chimères embryonnaires entre la caille et le poulet a été très utile pour l'étude du développement du système nerveux périphérique. En procédant à des greffes de territoire neural d'une manière systématique à tous les niveaux du névraxe entre ces deux espèces, nous avons pu déterminer le niveau d'origine des différents types cellulaires qui entrent dans la constitution des ganglions des systèmes nerveux autonome et sensoriel (figure 10A, p. 241).

Les crêtes neurales mésencéphaliques participent à la formation du ganglion trijumeau et du ganglion de racine du nerf facial, alors que les crêtes neurales rhombencéphaliques donnent naissance aux ganglions du complexe ganglionnaire jugulairesupérieur situé sur la racine des nerfs glossopharyngien et vague. 


\section{RÉFÉRENCES}

21. Fontaine J. Multistep migration of calcitonin cell precursors during ontogeny of the mouse pharynx. Gen Comp Endocrinol $1979 ; 37: 81-92$.

22. Couly G, Le Douarin NM. Mapping of the early neural primordium in quailchick chimaeras. I. Developmental relationships between placodes, facial ectoderm and prosencephalon. Dev Biol 1985; 110 : 422-39.

23. Couly G, Le Douarin NM. Mapping of the early neural primordium in quailchick chimaeras. II. The prosencephalic neural plate and neural folds : implications for the genesis of cephalic human congenital. Dev Biol 1987 ; 120 : 198-214.

24. Couly G, Le Douarin NM. The fate map of the cephalic neural primordium at the presomitic to the 3-somite stage in the avian embryo. Development 1988; 103 : 101-13.

25. Teillet MA, Kalcheim C, Le Douarin NM. Formation of the dorsal root ganglia in the avian embryo : segmental origin and migratory behavior of neural crest progenitor cells. Dev Biol $1987 ; 120: 329-47$.

26. Kalcheim C, Teillet MA. Consequences of somite manipulation on the pattern of dorsal root ganglion development. Development $1989 ; 106: 85-93$.

27. Le Douarin NM, Teillet MA. Localisation, par la méthode des greffes interspécifiques, du territoire neural dont dérivent les cellules adrénales surrénaliennes chez l'embryon d'oiseau. CR Acad Sci (Paris) $1971 ; 272$ : 481-4.

28. Le Douarin NM. Cell line segregation during peripheral nervous system ontogeny. Science 1986 ; 231 : 1515-22.

29. Baroffio A, Dupin E, Le Douarin NM. Clone-forming ability and differentiation potential of migratory neural crest cells. Proc Natl Acad Sci USA 1988 ; 85 : 5325-9.

30. Balaban E, Teillet MA, Le Douarin NM. Application of the quail-chick chimaera system to the study of brain development and behavior. Science 1988 ; 241 : 1339-42.

31. Kinutani M, Le Douarin NM. Avian spinal cord chimaeras: I. Hatching ability and post hatching survival in homo- and heterospecific chimaeras. Dev Biol 1985 ;

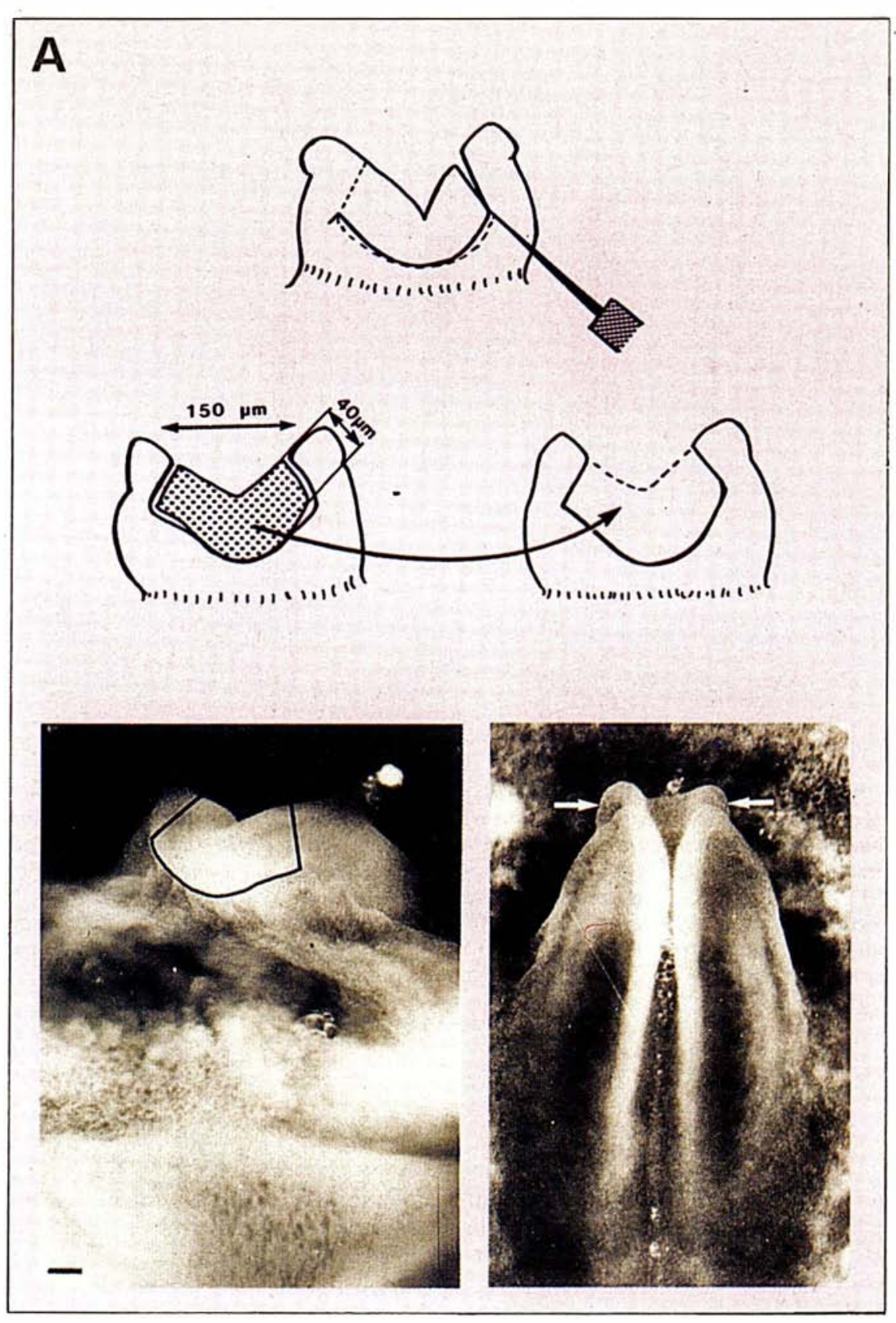

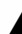

Figure 8. Origine de l'adénohypophyse. La greffe de bourrelet neural antérieur de caille chez le poulet est représentée en (A). La conséquence de cette greffe (B page 239) est le développement de la poche de Rathke à partir du territoire greffé. En B (page 239), la coupe sagittale de la tête de l'embryon chimérique de cina jours (a) montre que le fond de la poche de Rathke (b) et l'épithélium du toit du stomodéum (c) présentent le marqueur caille. 


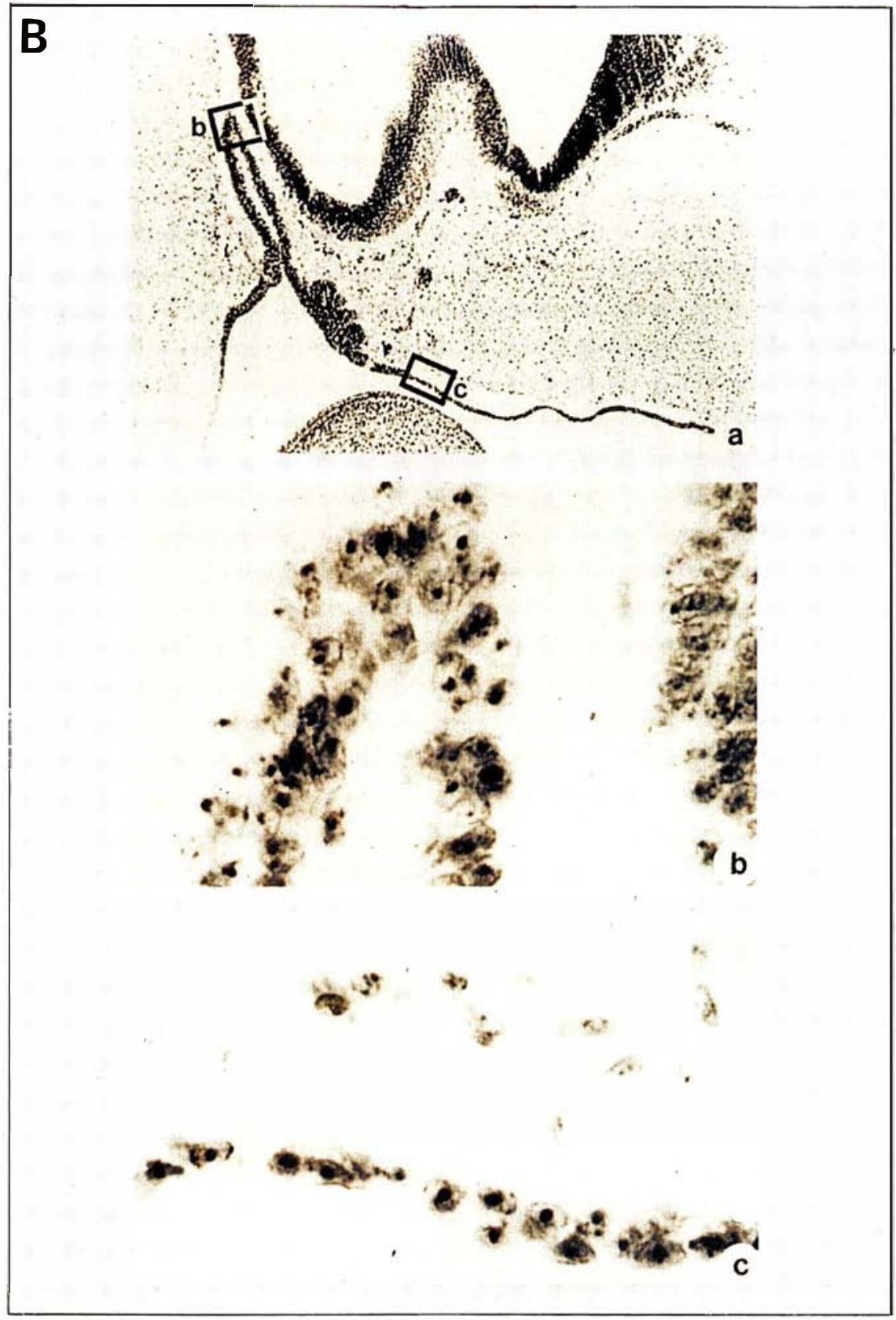

Les ganglions genouillé, pétreux et noueux proviennent quant à eux de placodes ectodermiques céphaliques. Aux niveaux cervical et troncal, les crêtes neurales fournissent les ganglions rachidiens. Nous avons pu montrer, par des manipulations du territoire somitique, que les précurseurs des ganglions sensoriels émergent d'une manière homogène le long du névraxe et que leur segmentation est dictée par la morphogenèse des somites [25, 26].

$\mathrm{m} / \mathrm{s} n^{\circ} 3 \mathrm{vol}, 6$, mars 90 nes des ganglions et plexus adrénergiques ainsi que les cellules médullosurrénaliennes de la glande surrénale (figure 11, p. 242). Celles-ci proviennent précisément du niveau des somites 18 à 24 [27].

Les ganglions parasympathiques entériques sont formés uniquement de neurones non adrénergiques, provenant pour la plus grande part des crêtes neurales vagales issues de l'ébauche neurale comprise entre les somites 1 à 7. Quelques cellules provenant de l'ébauche neurale postérieure au $28^{e}$ somite ont été trouvées dans les plexus du tube digestif postérieur [12]. Cette zone postérieure de l'ébauche neurale fournit aussi le ganglion parasympathique de Remak.

Il apparaît donc que la crête neurale est divisée en régions qui fournissent seulement un nombre limité de types cellulaires parmi ceux qui composent le système nerveux périphérique (figure 10A, p. 241). Par exemple, le territoire compris entre les somites 7 et 28 ne participe qu'à la formation des ganglions sensoriels et sympathiques adrénergiques, mais il n'intervient pas dans le développement du système parasympathique. Cependant, si on modifie la position des cellules de la crête neurale le long du névraxe avant qu'elles n'aient commencé à migrer (figure 12, p. 242), on peut changer leur destinée. Ainsi, le territoire vagal dont sont issues normalement les cellules du système nerveux entérique peut être transplanté dans la zone troncale au niveau des somites 18 à 24. Dans ces conditions, les cellules normalement destinées à migrer dans l'intestin se localisent dans les ganglions sympathiques et la glande surrénale où elles expriment le phénotype adrénergique. Les cellules de la zone troncale transplantée dans le territoire vagal migrent dans l'intestin et s'y différencient en cellules parasympathiques dont le médiateur principal est l'acétylcholine [13]. Ainsi, nous montrions que l'environnement tissulaire dans lequel se différencient les cellules de la crête neurale est décisif dans le choix du neurotransmetteur qu'elles synthétisent.

En réalisant de telles expériences, à différents niveaux de l'axe neural, nous avons pu montrer que la capacité de différenciation des cellules de 


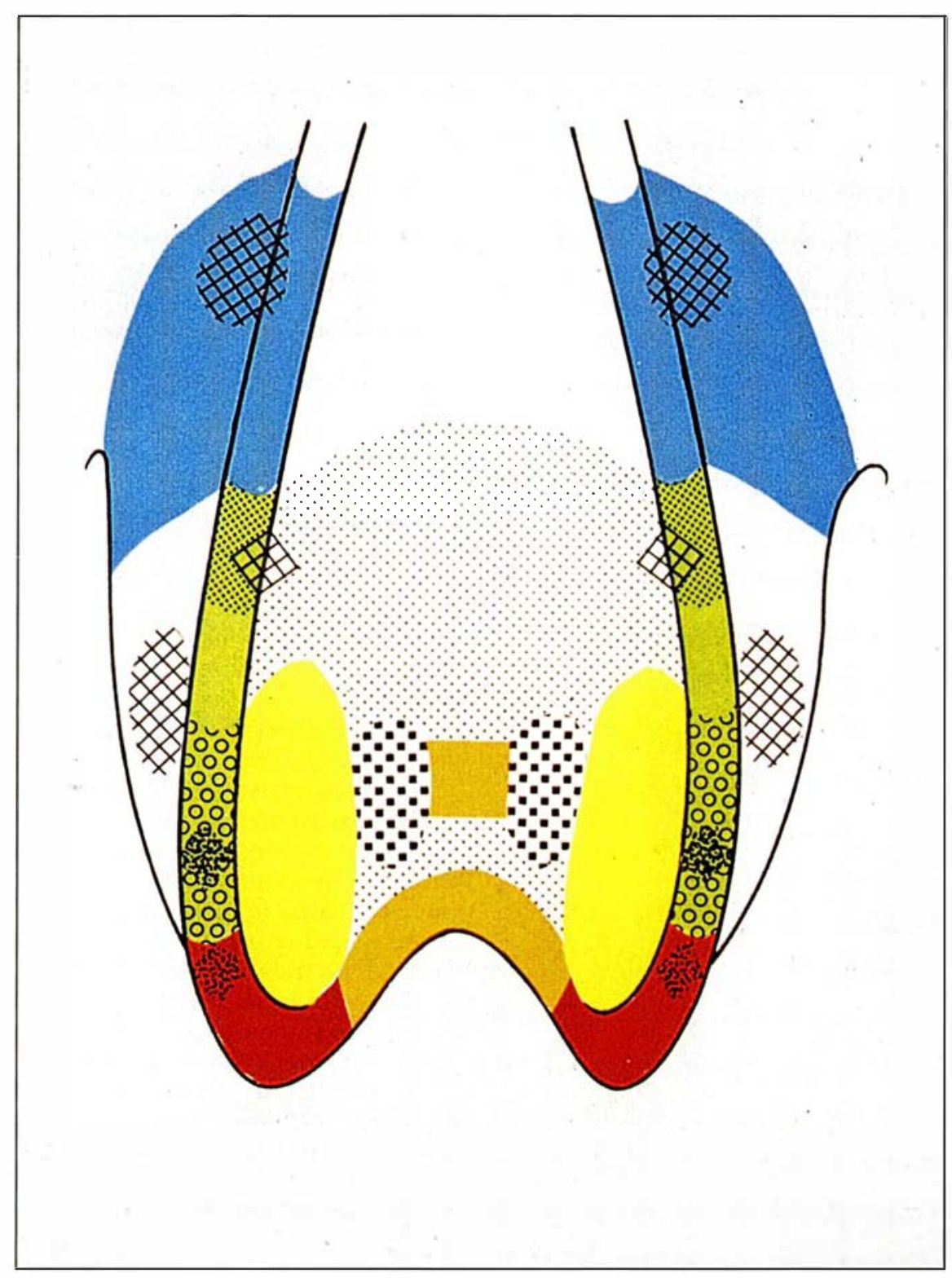

Figure 9. Cartographie des territoires du bourrelet neural céphalique et de la plaque neurale, au stade neurula, obtenue par greffes de régions limitées de cette ébauche de la caille chez le poulet. En orange, les territoires de l'adénohypophyse et de la neurohypophyse entourant celui de l'hypothalamus en blanc. En rouge, l'ectoderme de la cavité nasale avec en pointillé la placode olfactive donnant naissance à l'épithélium olfactif et au nerf olfactif. Les damiers entourant le territoire de la neurohypophyse représentent les vésicules optiques, avec de chaque côté, en jaune, le toit du télencéphale. La zone pointillée en arrière des vésicules optiques et du télencéphale représente le diencéphale. En vert, l'ectoderme du bec supérieur et de la peau du crâne avec le toit de l'épiphyse en pointillé dans sa partie la plus postérieure. En bleu, les crêtes neurales mésencéphaliques, au niveau du bourrelet, et l'ectoderme maxillaire et lingual, latéralement. la crête neurale est beaucoup plus étendue que celle qu'elles expriment au cours du développement normal. La comparaison de la carte du territoire présomptif du système nerveux autonome représentée sur la figure $10 \mathrm{~A}$ avec celle des potentialités de développement des cellules de la crête neurale (figure $10 B$, p. 241) est très suggestive à cet égard : virtuellement, toutes les régions de la crête neurale peuvent fournir la totalité des phénotypes rencontrés dans le système nerveux périphérique, à condition qu'elles soient transplantées dans la région appropriée du névraxe.

L'importance de l'environnement dans lequel se différencient les cellules de la crête neurale était ainsi démontrée. Plusieurs lignes de recherche ont été poursuivies au vu des résultats de ces expériences. Elles consistent dans la recherche de la nature des facteurs tissulaires capables d'influencer la différenciation des neurones du système nerveux périphérique ([28] pour revue) et à rechercher quel est l'état de détermination des cellules de la crête neurale par des cultures clonales.

Ces dernières expériences [29] nous ont révélé l'existence de cellules souches capables de fournir des clones dans lesquels tous les types cellulaires rencontrés dans les dérivés de la crête neurale sont représentés. Il apparaît également que, pendant leur migration, ces cellules se multiplient abondamment. Au cours de ces divisions, leurs potentialités de différenciation se restreignent considérablement selon un modèle comparable à celui qui préside à la différenciation des cellules du système sanguin.

\section{Cerveaux chimères}

$\mathrm{Au}$ début du deuxième jour de l'incubation, le cerveau des oiseaux a la forme d'un tube à peine élargi antérieurement au niveau des ébauches oculaires. Par la suite, ce tube, constitué d'un épithélium pluristratifié, acquiert des constrictions qui limitent les grandes vésicules du cerveau antérieur (prosencéphale), moyen (mésencéphale) et postérieur (rhombencéphale). Au cours du deuxième jour de l'incubation (stades de 12 à 15 paires de somites), l'ébauche du cerveau d'oiseau est parfaite- 


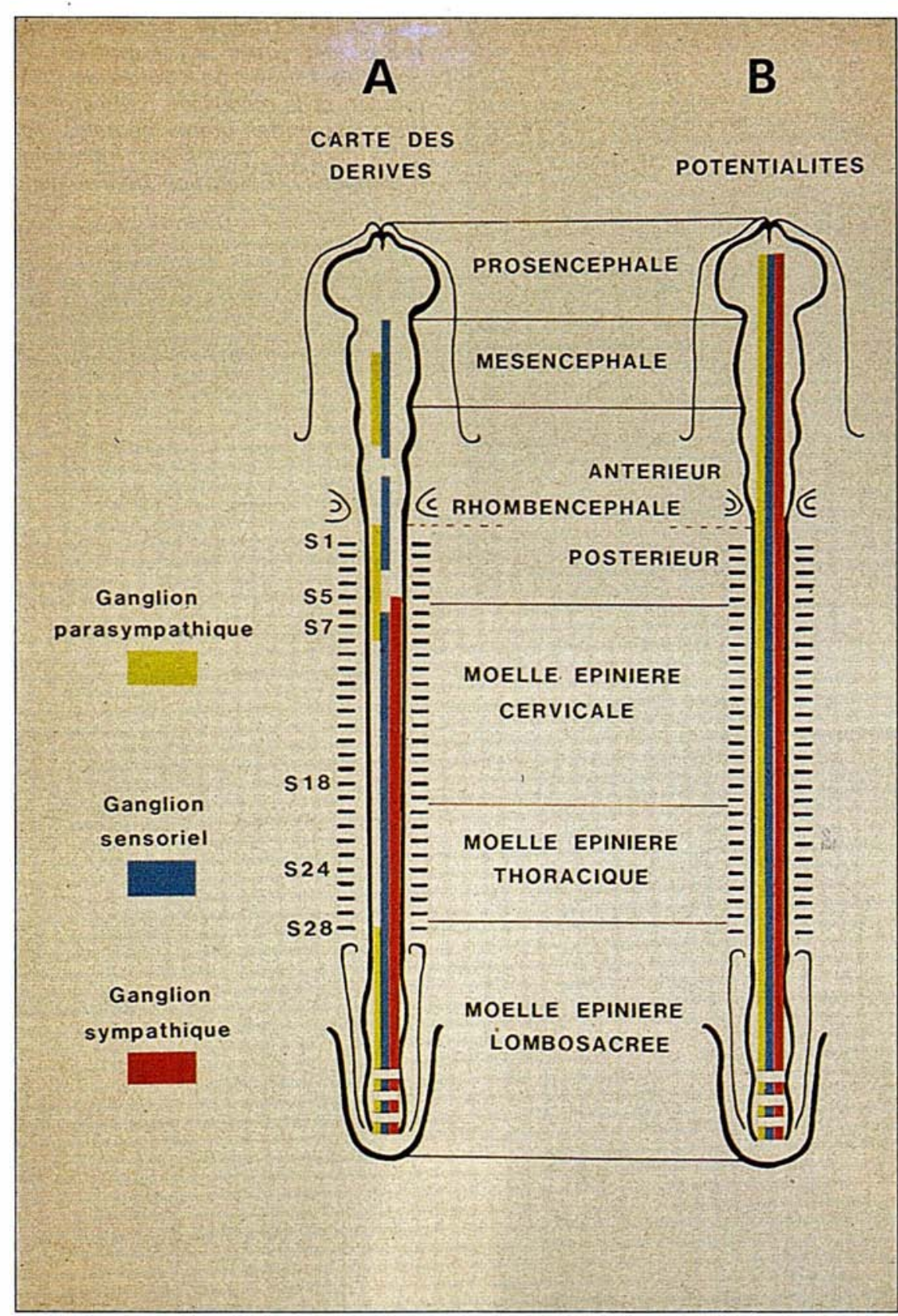

Figure 10. (A) Cartographie de l'origine des différents dérivés des crêtes neurales. En bleu, les neurones sensoriels issus des crêtes neurales mésencéphaliques et rhombencéphaliques pour les ganglions crâniaux et des crêtes neurales cervicales et troncales pour les ganglions rachidiens. En rouge, les neurones et paraganglions adrénergiques issus des crêtes neurales postérieures au $5^{\circ}$ somite. En vert, les neurones cholinergiques issus des crêtes neurales vagales antérieures (somites 1 à 7) et postérieures (somites 28 et postérieures). Ce schéma montre qu'en ce qui concerne le système nerveux autonome, le niveau vagal (somites 1 à 5) a une vocation purement parasympathique alors que le niveau troncal (entre somites 6 et 28) a une vocation purement sympathique. (B) Potentialités des crêtes neurales mises en évidence par des greffes hétérotopiques. En réalité, les potentialités adrénergiques (rouge) et cholinergiques (vert) paraissent largement réparties le long de l'axe nerveux, comme la capacité de fournir des neurones sensoriels (bleu).

$\mathrm{m} / \mathrm{s} n^{\circ} 3$ vol. 6 , mars 90 ment accessible à la microchirurgie. Il est possible d'échanger des régions limitées de l'épithélium neural entre la caille et le poulet afin de marquer des territoires choisis. Il est possible également d'effectuer des échanges de grandes régions, voire du cerveau tout entier, entre ces deux espèces ou entre des poulets présentant des caractères génétiques différents. Le développement ultérieur des cerveaux chimères est conforme au développement normal et les animaux opérés peuvent éclore.

L'intérêt de telles opérations est double. Elles permettent d'étudier les migrations cellulaires se produisant au sein de l'épithélium neural au cours de la morphogenèse cérébrale. Divers types de chimères encéphaliques ont été construits dans ce but [30]. Si, par exemple, la région dorsale du télencéphale et/ou du diencéphale est greffée de la caille chez le poulet (ou inversement), on peut suivre l'évolution des territoires greffés dans des conditions privilégiées puisque des observations sont réalisées à divers stades du développement jusqu'après l'éclosion. La reconnaissance des cellules de caille et de poulet par la coloration de Feulgen et par l'utilisation d'anticorps spécifiques de chaque espèce a permis de voir que les migrations cellulaires au sein du neuroépithélium ne s'effectuent pas d'une manière strictement radiale, comme on le croyait généralement. La limite de greffe, toujours visible au niveau de l'épithélium ventriculaire, devient de plus en plus floue dans l'épaisseur du manteau où les cellules neuronales et gliales des deux espèces se mélangent sur de grandes distances, mettant ainsi en évidence des migrations tangentielles de grande amplitude qui s'ajoutent aux migrations radiales déjà connues.

Le deuxième intérêt de ces expériences est de voir si le remplacement de régions du cerveau de poulet par leur équivalent provenant de la caille peut avoir pour "conséquence le transfert de traits comportementaux spécifiques de la caille. Le comportement choisi a été le chant tel qu'on peut l'induire chez le poussin par des implants sous-cutanés de testostérone. Des différences quantifiables et évidentes de la structure du chant existent en effet entre ces deux espèces. 


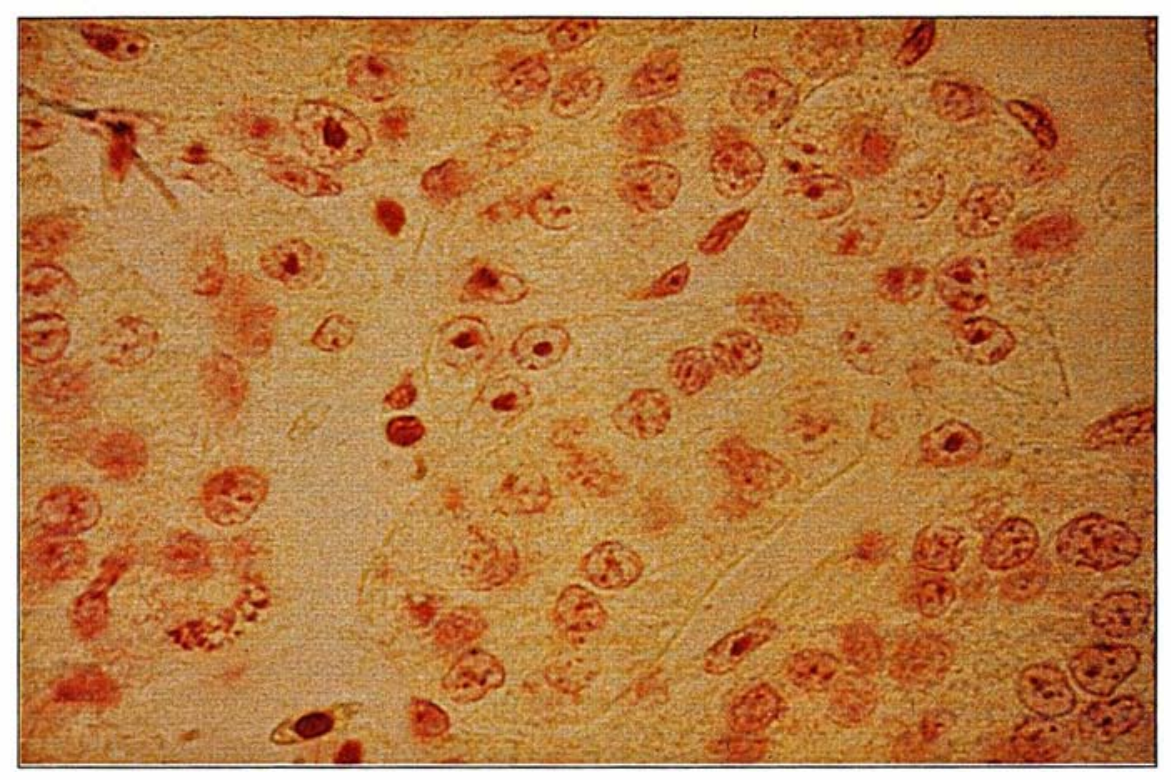

Figure 11. Glande surrénale chimère (14 jours d'incubation). La corticale formée de cellules de l'hôte (poulet) et la médullaire formée de cellules issues des crêtes neurales troncales greffées (caille) sont intimement mélangées. (Coloration de Feulgen.)

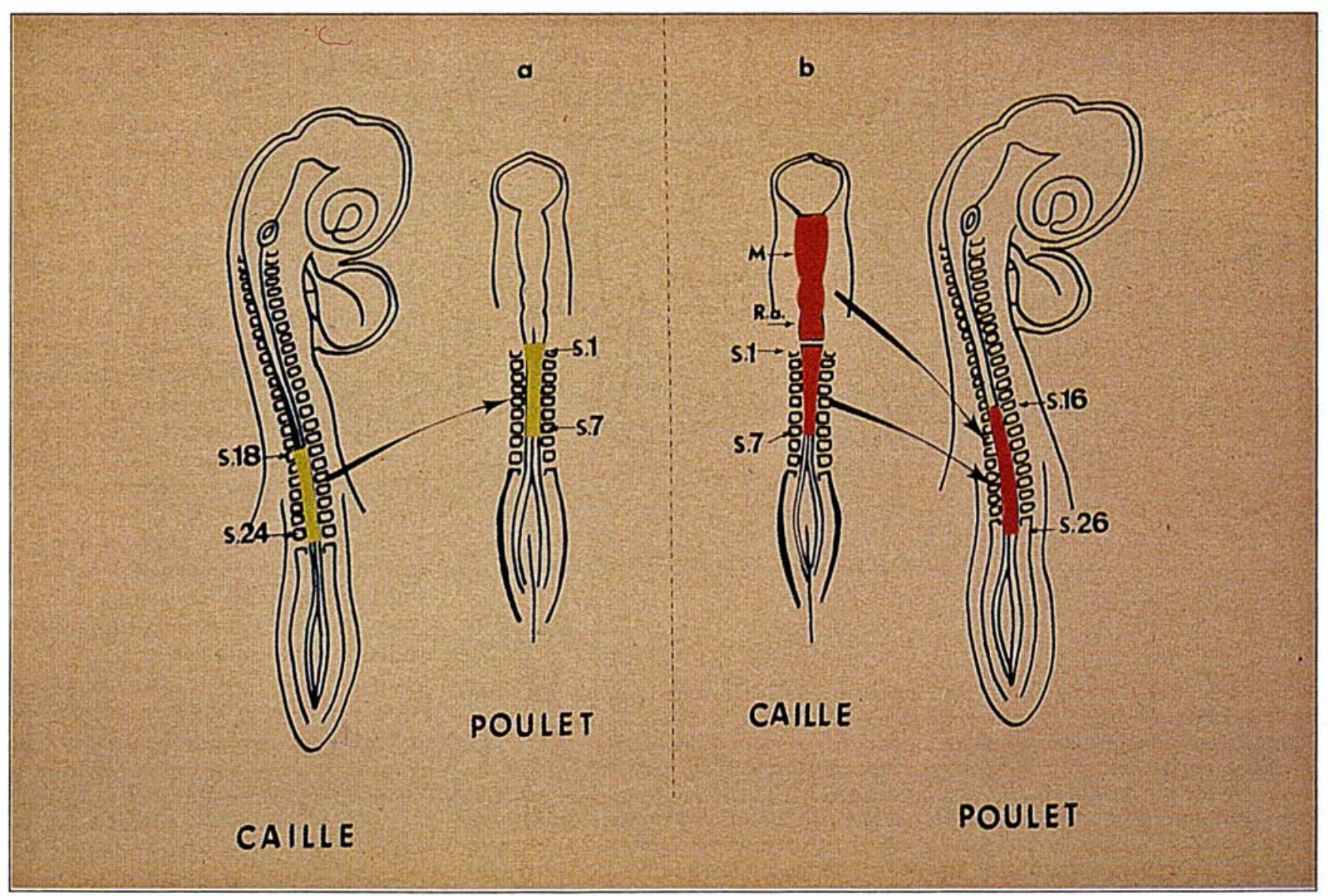

Figure 12. II est possible de transplanter un tronçon de l'ébauche troncale au niveau vagal (a) ou l'ébauche neurale vagale au niveau adrénomédullaire (b). Dans ce cas, les donneur et receveur sont d'âges différents. On parle alors de greffes hétérotopiques et hétérochroniques par opposition aux greffes isotopiques et isochroniques que l'on fait habituellement pour étudier le développement normal. Ce type de greffe fait apparaître les potentialités de développement des crêtes neurales qui sont indiquées dans la figure $10 B$. 


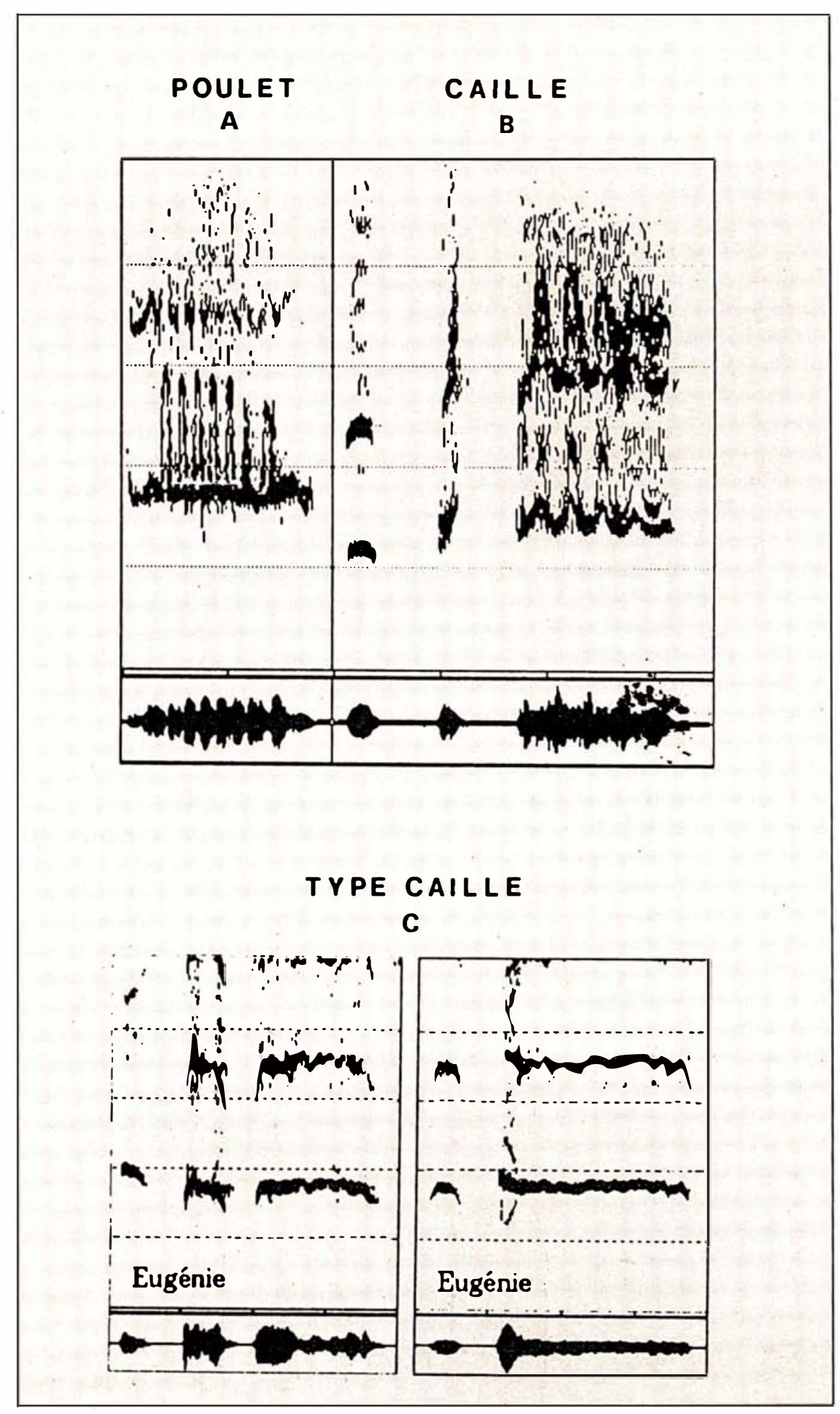

Figure 13. Sonogrammes du chant induit par la testostérone chez de jeunes poussins. Chaque sonogramme représente une vocalisation qui est caractérisée chez le poulet (A) par une émission unique, chez la caille (B) par une émission principale précédée d'une ou deux notes courtes. Chez des chimères ayant eu une greffe de la région moyenne du cerveau de la caille (diencéphale plus mésencéphale), on a pu enregistrer un chant structuré comme celui de la caille. Les sonogrammes présentés en (C), typiques de la caille, sont ceux de la chimère présentée sur la figure 6B.

$m / s n^{\circ} 3$ vol. 6, mars 90
Notamment, le chant du poulet est constitué d'une vocalisation unique alors que celui de la caille est segmenté en trois parties : deux notes introductives séparées d'une vocalisation plus longue (figures $13 B$ et 13C). Les chimères écloses de cette série expérimentale ont montré que l'échange de la région dorsale du prosencéphale entre caille et poulet n'a aucune conséquence sur la structure du chant. Les chimères de ce type ont un chant non segmenté comme les poussins normaux.

$\mathrm{Si}$, au contraire, une région plus large du cerveau, comprenant au moins le pro- ou le mésencéphale et le rhombencéphale, est implantée, les chimères obtenues émettent un chant segmenté caractéristique de la caille (figures $13 B$ et 13C).

Ceci constitue la première démonstration que le transfert d'un trait comportemental génétique peut être effectué à l'aide de greffes de tissu neural [30]

\section{Perspectives}

Les recherches décrites ici ne représentent qu'un des aspects des problèmes que l'on peut aborder à l'aide des chimères embryonnaires. Dans l'étude de la crête neurale, cette méthode a permis d'obtenir des renseignements précis sur la morphogenèse céphalique, l'origine de certaines cellules endocrines et le développement du système nerveux périphérique. A cet égard, elles nous ont aussi amenés à définir des questions précises sur les mécanismes de la différenciation des neurones et des cellules gliales qui composent le système nerveux périphérique. Ces problèmes font maintenant l'objet d'études au niveau moléculaire et nous ont amenés à concevoir des protocoles expérimentaux impliquant le transfert en culture in vitro des systèmes cellulaires considérés.

Nous avons aussi pu étudier les phases précoces du développement du système immunitaire et aborder l'étude des mécanismes qui assurent la distinction du soi et du non-soi. En effet, le statut immunologique des greffes réalisées au cours de l'embryogenèse précoce pose le problème de la tolérance sous un angle nouveau. Enfin, la ligne de recherches récemment développée sur la morphogenèse cérébrale nous paraît prometteuse

(Summary page suivante) 


\section{Summary}

Embryonic chimeras and development of the nervous system

Chimeras have been constructed in the avian embryo using the particular structure of the quail cell nucleus as a marker. In quail cells a large amount of heterochromatin is associated with the nucleolus whereas in the chick cells heterochromatin is evenly dispersed in the nucleoplasm during the interphase. Replacing a portion of the neural anlage of a chick embryo by its quail counterpart definitively labels the part of the nervous system which arises from it. This technique has enabled the exact origin of different parts of the peripheral nervous system to be determined and has demonstrated the plasticity of its precursor cells. In a similar way, by interspecifically grafting brain vesicles it is now possible to approach problems related to the construction of the brain and to the genetic origin of certain behavioral patterns.

\section{TIRÉS A PART}

N. Le Douarin. 